\title{
The Adequacy of Environmental Education Techniques and Strategies Employed in Uluguru Mountains Hotspot
}

\author{
Joseph Manase \\ Department of Educational Foundations and Continuing Studies, College of Education, the University of Dodoma, Tanzania \\ E-mail: manassehjoseph2@gmail.com
}

Received: 14-06- 2016

Accepted: 06-10-2016

Published: 31-10-2016

doi:10.7575/aiac.ijels.v.4n.4p.65

URL: http://dx.doi.org/10.7575/aiac.ijels.v.4n.4p.65

\begin{abstract}
Various studies about the environment consider different factors as sources of environmental deterioration. Such studies have not paid much attention on education as the remedy for environmental sustainability. Other studies have rarely considered environmental education approaches as the reason for lack of success in environmental education arrangements. This research had a focus on the adequacy of environmental education approaches, techniques and strategies employed in Uluguru Mountains in Morogoro. Social constructivist theory by Vigortsky (1958) was employed while case study research design and qualitative approach were deemed important for this research. Data collection was done by using interview and Focus Group Discussion methods. Objectives of the research were to: investigate adequacy of Environmental Education content, methods, awareness as well as the use of indigenous environmental knowledge. The findings show that, environmental education methods implemented in Uluguru Mountains are not satisfactory enough to improve environmental conditions. Again, indigenous knowledge has been less integrated into Environmental Education. Different environmental education methods need to be improved and integrated to create sustainable learning outcomes within Environmental Education.
\end{abstract}

Keywords: Adequacy, Environmental Education, Approaches, Strategies, hotspot

\section{Introduction}

Most studies in developing countries (Okwu \& Daudu, 2011 cited in Israel, 2006; Hosseini, 2010; FAO, 2006; Mosimege, 2005) point out that developing an understanding of extension sources and channels used to obtain information is the pre-requisite for efficient educational approaches. The implementation of $\mathrm{EE}$ in various hemispheres of the world has been as well showing a significant difference in terms of methods of delivery, that is, techniques and approaches employed in educating communities about the wellbeing of their environment (FAO, 2006). Therefore, while EE in developing world focus mostly on changing individuals' attitudes towards the environment (Dillon \& Teamey, 2002; Gough, 1997; Hart, 1993), Environmental Education in the developed world shows a significant shift of dealing with creation of awareness and sensitization about environmental changes such as climate change and ways of mitigating it as fraudulent natural hazards.

Furthermore, effective EE system and techniques have not been practiced widely in formal and informal context because it is complex and too demanding. Besides, this has an implication that EE methods and awareness should be instigated to the people in order to enhance sustainable environmental conservation. However, it is assumed that the community is supposed to be aware of the power and potential of EE in mitigating deforestation and for that reason halt environmental degradation (Dillon \& Teamey, 2002; Gough, 1997; Reynolds, 2011). In order to understand the effectiveness of EE methods used in communities, it is suggested by Marcinkowski (2010) that communities should participate in developing a mechanism for choosing the appropriate methods that fits the need of their environment. This is based on the understanding that EE methods are context specific. For example, EE techniques and approaches employed in conserving aquatic, terrestrial and atmospheric environment may differ vastly as the environmental components themselves (FAO, 2010).

Studies by Stevenson (2010) and Roth (1992) suggest that the conditions needed to support Environmental Education are rarely found in formal situation rather they can be better implemented in formal and informal contexts using group, mass and individual methods of community extension. They seem to suggest relevant strategies of teaching EE such as exhibition and displays, public service announcements, environmental interpretation program, learner designed investigations, simulations and role plays, community service program, action research, multiage teaching and case studies. These methods have been criticized in other studies by Gardner (2009) as being too demanding in terms of time, technology and they incurs a lot of financial costs during its implementation. This was observed to be true due to the rural settings in the remote communities.

Ferreira (2009) found that in order for environmental education to be transformative to different communities, some traditional community learning models such as ideological ancestry of the liberation, transactional models of rural 
community, the narrative models or strategies have to be employed in order to change the ways of thinking and practice of people towards environmental sustainability and ultimately the achievement of sustainable development. Furthermore, Ferreira (2009) points out that, sustainable development, the major focus of Environmental Education, will only be reached by integrating (blending) different environmental conservation methods, techniques and strategies in combating especially the problem of deforestation.

The range of these methods is from formal, informal to non-formal as well as traditional. Stenberg (2010) defines on the continuum method, which is characterized by observable behaviors in community learning; Functional environmental literacy: where learners who achieve this level possess a broader knowledge and understanding of interactions between human social systems and natural systems. Operational environmental literacy: where learners who achieve this level move beyond functional literacy in the breadth and depth of understanding and skills. Ineffective Environmental Education approaches are believed to be the means and end of most of the environmental problems facing the globe (Stevenson, 2010). Therefore, it was important to conduct this study in order to suggest effective methods of mitigating environmental problems in the Uluguru Mountain in Mororgoro, Tanzania.

\subsection{Problem Proclamation}

Environmental education performance is one of the questions that have not been critically studied (URT, 2007). Choice of the methods to be employed in educating particular communities is seen to be a complex process that needs a clear understanding of the people and their environment. Environmental education practice in Uluguru Mountains has not been effective due to some factors. A lot of literature exists on EE such as (Stevenson, 2010; Stenberg, 2010; Marcinkowski (2010); Dillon \& Teamey, 2002; Gough, 1997; Kimaryo, 2011; Mosimege, 2005; Okwu \& Daudu, 2011 in Israel, 2006; Hosseini, 2010; FAO, 2006). However, very little has been studied on the adequacy of EE methods in Uluguru Mountains.

\subsection{Study Objectives}

Based on this study the main objective was to assess the adequacy of environmental education methods implemented in the Uluguru Mountains. More specifically, the study sought to investigate on approaches and techniques employed in teaching Environmental Education in the community as well as to what extent are indigenous conservation knowledge is integrated in EE programs.

\section{Methods}

The nature of the study objectives prompted the adoption of the case study design in which qualitative research approach was adopted. The study was conducted in Morogoro region, in the Uluguru Mountains in Tanzania. The rationale for selecting this study area is that, Uluguru Mountains are rich in biodiversity of the global interests. They support a lot of animal and plant species of ecological importance. The Mountains are part of the Global Climatic Hotspots. Most of the rivers from these Mountains are the source of water for Dar-es-Salaam City, Coastal region and Morogoro region itself. This means that the forests of the Mountains need to be protected through a combination of various local and global conservation strategies. The study population involved environmental educators and members of the community of the stated research area. Environmental educators were used in order to reveal strategies and techniques employed in educating the community about the environment, while community members were drawn in order to cross-link the information about methods used by environmental educators.

Purposeful and snowballing sampling was employed to draw the sample of 20 respondents in total. Of this sample size, 10 respondents were environmental educators from Non-Governmental Organizations and Community-Based Organizations. Environmental educators responded to the structured interview whereby the interview schedule was predetermined with questions related to the research objectives. A total of 10 respondents were drawn from the community and they formed a Focus Group Discussion (FGD). Members of the Focus Group were sampled based on their experience of the study area and participation in Environmental Education activities that have been taking place in the study area. Content analysis was employed in analyzing qualitative data collected from Focus Group Discussion (FGD). Triangulation of data sources and data collection methods was done to ensure validity and reliability. Findings were presented thematically with the following headings: Environmental program content, Environmental Education learning and teaching strategies.

\section{Results}

\subsection{Adequacy of Environmental Education Program Content}

Data from interviews with environmental educators mentioned that they learnt from Environmental Education programs and results indicated the content to be based on prevention of land degradation, protection of forests, effects of fire in animal hunting, tree planting as well as bee keeping skills. One of the educators reported that, "they educate the community to keep bees, establish forest farms, vegetable gardening and sustainable agriculture farming for those who live in the mountains. They also train them to identify and plant tree species which are environmentally friendly i.e. do not cause drought to the land such as griveria spp, msederea, mkuyu, mkangazi etc" (Environmental educator from Uluguru Mountains Agricultural Development and Environmental Protection Project). Also, an educator commenting on the content of EE programs said that: "They teach people how to make brick stoves, which use firewood but in an 
effective and efficient way. They use small amount of firewood to cook large amount of foodstuff, and therefore they are assumed to reduce the amount of trees cut down annually" (Environmental Educator from CARE International, 2013).

Data from the Focus Group Discussion (FGD) with five elders from Bigwa, Misongeni and Choma revealed that, most of the Environmental Education content delivered during community environmental education programs was not focusing on giving alternative livelihood apart from discouraging people from cutting down forests for firewood and other uses, as one of them from the Bigwa reports, "Although there has been a lot of EE taught in the communities, rarely educators did not tell them on what should be an alternative energy source. What they did was to discourage us from cutting down trees for fire wood". Another participant from Choma reported that "during Environmental Education meetings, people with different political ideologies introduce their political affiliations; this detracts the main theme of the meeting and disturbs members who have come for the purpose of attending Environmental Education programs."

\subsection{Environmental Education Teaching and Learning Strategies}

Results show that communities learn how to conserve their environment by doing conservation activities in the field, using pictures, traditional dances, seminars and workshops as well as cinema and videos. In support to the previous results, interviews were conducted with one of the environmental educators from Uluguru Mountains Nature Conservation who reported that: "they use village meetings mostly to educate people about forest conservation. Other methods that are applied are training village leaders, environmental groups, and religious as well as traditional leaders through seminars, workshops and public lectures".

\subsection{Integration of Indigenous Knowledge in EE Program}

Based on the use of indigenous knowledge in promoting environmental conservation, a participant from Tangeni in the Focus Group reported that "the community does not use indigenous knowledge in environmental conservation. They claim that western education has become dominant for so many years."

In general, they report that, in the past, traditional leaders, healers and elders who had knowledge of conservation in certain environmental aspects such as animals, forests, water bodies or soil were allowed to facilitate environmental education. There were people who had specialization in rain making, wind breaking, sustainable animal hunting, prediction of good and bad events which were related to calamities of the nature and the environment." (Facilitator 3, from Choma ward).

One of the discussants highlighted that, indigenous environmental education used to be delivered mainly through folklores or story tales as he reports that: "Folklores or story tales are the main methods through which indigenous Environmental Education was being delivered in the community. For example, facilitators of traditional Environmental Education were giving tales of the presence of certain strange creatures in the forest such as presence of mysterious snakes, beautiful woman in the forest with a single breast. Other folklores were about the giants living in specific tree species, for instance baobab trees, if you cut the tree down, you were likely to be killed by the evil spirits because those trees were believed to be the spirit dwelling places (F2, B).

\section{Discussion}

The findings indicate that the community is aware of the environmental education programs that have been taking place in their community. It seems however that, less participation has been experienced. Participants reported that they usually do not take part in recommending the methods to be employed. Poor preparation for environmental programs taking place in the community seems to be the reason for poor implementation of effective methods and techniques.

These results reflect those by (Dillon \& Teamey, 2002; Gough, 1997) who argue that effective environmental education methods and techniques have not been practiced widely in formal and informal context because it is complex and demanding, intellectually and emotionally. Therefore, environmental education methods and awareness can better be instigated to the young generation in order to enhance sustainable environmental conservation. Again, it was informed that the community in the Uluguru Mountains had not been made aware of the power and potential of Environmental Education in mitigating deforestation, for that reason, forest degradation continues. Effective environmental education methods are those which provide room for evaluation and decision making on the impacted groups of the community who are the key beneficiaries (NAAEE, 1996; 1999; 2000).

The content of environmental education programs in the Uluguru Mountains was found to transform the community in terms of one domain of learning, the psychomotor domain. To be effective, the content was supposed to be planned to change both domains of learning, that is; the cognitive, affective as well as psychomotor domain (Palmer, 1998). The highly frequently mentioned content of environmental programs was that of tree planting, while the least mentioned was that of seeking permit in order to access forest resources both of them focusing on only psychomotor domain.

Findings from interviews with environmental educators showed that there were varied contents employed in educating the community on environmental conservation. Educators claimed to impart environmental knowledge and skills on bee keeping, forest farming, and vegetable gardening. They also taught sustainable agriculture farming for those who live in the mountains, such as terracing or contour farming. Palmer (1998) argues that environmental education methods and techniques should provide experience of problem-solving, decision-making and participation, with considerations based 
on ecological, political, economic, social, aesthetic and ethical aspects. It is also about promoting changes in behavior that helps to solve existing problems relating to the environment and to avoid the creation of new ones.

Moreover, the findings also concurs with those of Reynolds (2011) who state that the concretization process helps learners to realize that environmental conditions are constructed by people's decisions and by the same indication, they are able to reconstruct their environment to overcome undesirable elements and improve the quality of life. It can therefore be understood that Knowledge in education for the environment is constructed with the purpose of it being useful in day-today experiences, to be socially relevant and be applicable in the resolution of environmental issues. Likewise, methods employed in teaching environmental conservation in the community would be contextualized to fit people's wishes and demands in meeting what they perceive as sustainable development (UNEP, 2008).

Again, environmental program content acquired by the community in the Uluguru Mountains was seen as being providing a narrow knowledge, ineffective towards change of attitude and practice on Environmental Education and hence considered as insufficient in solving environmental problems such as deforestation. Therefore, environmental learning is important at all stages of life, and Environmental Education is a lifelong learning Endeavour. These findings do not concur with those suggested by Roth (1992) who describes environmental literacy as a continuum of competencies, understanding, skills, and actions, rather than a discrete attribute that one either does or does not possess. In order to be effective program content is supposed to be determined by the community participants themselves so as to avoid top down approach that impedes sustainable learning and ultimately sustainable environmental conservation.

Moreover, the findings diverge away from those of Roth (1992) who defines three points of continuum, each of which is characterized by observable behaviors. Each successive point on the continuum represents an increased level of sophistication with respect to environmental learning and behavior. Functional environmental literacy: Learners who have achieved this level possess a broader knowledge and understanding of interactions between human social systems and natural systems. They are also aware of and concerned about negative interactions between human and natural systems in terms of one or more issues. They can as well analyze, synthesize, and evaluate information about issues using primary and secondary sources. They communicate findings and feelings to others and demonstrate a motivation to work toward solutions to environmental problems by using basic strategies for social or technological change.

Learners who have achieved operational environmental literacy have moved beyond functional literacy in the breadth and depth of understanding and skills. Routinely evaluate impacts and consequences of actions. Gather and synthesize pertinent information, choose among alternatives, and advocate positions and actions that work to sustain or enhance a healthy environment. Demonstrate a strong, ongoing sense of investment in and responsibility for preventing or remediating environmental degradation. Act at several levels, from local to global, and routinely engage in dealing with the world at large.

Group methods used in providing environmental education were found to cover only one category of transforming the community. Mass, and individual methods of educating the community were less employed. The findings coincide with the study by Stevenson (2007) who argues that, the conditions needed to support EE are rarely found in formal situation. Roth (1992) also suggest more strategies of teaching EE such as exhibition and displays, public service announcements, environmental interpretation programs, learner designed investigations, simulations and role plays, community service programs, action research, multiage teaching and case studies.

Usang (1992) comments that in order for environmental education to be effective and efficient in transforming the community towards forest conservation some community learning models such as ideological ancestry of the liberation, transactional models of rural community, the shopping basket model and narrative models or strategies have to be employed in order to change the ways of thinking and practice of people towards the environment. Against the findings again is the study by Roth (1992) and FAO(2010) who suggests the use of forest extension methods such as mass methods which include meetings, radio, television newsletters, posters, public announcements, and individual extension methods which involves office and home visit, tracts, and individual telephone contact.

The methods used in community Environmental Education were found to be inadequate. The evaluation of knowledge and skills provided in the mass context had some shortcomings since it did not embrace the environmental education extension philosophy of teaching through triangular approach of using mass, group and individual techniques as suggested by FAO (2010). Also evidence has shown that environmental education provided in the Uluguru Mountains did not employ a combination of formal, informal and non-formal educational approaches. This could be assumed as one of the shortcomings of the method employed in the research area. Also, there wasn't integration of the methods used in formal and informal contexts. The findings are against the findings by Osak (1991) and Kimaryo (2011), who found that there was a need to integrate environmental education in secondary and primary school in Tanzania respectively.

Participants of the FGD reported indigenous knowledge to have been less integrated and practiced in the community. In some communities; this knowledge was believed to have been used in the past. These findings do not match with those of Mosimege (2005) who claim that indigenous EE has been used in environmental conservation and it has been effective in improving and sustaining forest conditions. These arguments are supported by the findings by UNEP (2008) which argued that many of the indigenous knowledge approaches to environmental conservation have been very effective in reclaiming environmental conditions. 
The study by Edje (2004) points out that indigenous knowledge in forest conservation provides valuable insights on how communities have interacted with their local environment. Unfortunately, indigenous education systems in Tanzania have not been systematically recorded and is therefore not readily accessible to policy makers, researchers and development agents, although several writers have provided detailed overviews of indigenous knowledge systems in agricultural development, pastoral management, and agro-forestry.

It was also highlighted that protection of water resources, forest conservation, trees with medicinal value, and general education on the importance of environment are the contents that were mentioned in the indigenous curricula. To the critique, the contents mentioned were those which were taking place in the modern environmental practices. Therefore, there was no clear difference between the content in the indigenous Environmental Education and the contemporary approaches. In regard to this, indigenous Environmental Education was found to be less integrated in Environmental Education programs. This was against the broader focus suggested by UNEP (2008) that considers indigenous Environmental Education to cover such areas as environmental conservation, disaster management, poverty alleviation and traditional medicine practices.

It is therefore evident that the lay group need to have attitudes, philosophies and values about the environment. Each of these in turn requires different teaching strategies which have to be carefully utilized by environmental educators. For the Technical Group, practical experimental teaching methods based on the traditional subject approach appear to be the most suitable. The Subject Specialist Group needs presentational methods based on either an infusion approach or a new subject approach. For the Management Group, a combination of high level disciplinary teaching combined with intensive short skills courses and more extensive 'junctions' or 'environmental encounters', all of which make use of practice methods of teaching, are suggested. From these observations above, Dillon et al., (2006) suggest the Lay Group, experiential methods, where the student's attitudes are challenged by experiences in either an in-service situation or through simulation.

\section{Conclusion and Recommendation}

It was clear that communities in the Uluguru Mountains were aware of the environmental education programmes and activities' going on in the study area but they had poor participation in such Environmental Education programs. The methods and program content were also reported inadequate and less transformative. The findings revealed further the lack of comprehensive integration of formal, informal and non-formal approaches in environmental education. It is due to the fact that indigenous knowledge was less employed in educating communities about their environment and conservation. It is therefore recommended that formal, informal and non-formal approaches of environmental education have to be integrated with indigenous knowledge so as to make environmental education learning more meaningful and effective. There is also the need to use the methods that transforms both psychomotor, affective and cognitive domains and be integrated into environmental education.

\section{References}

Dillon, J., Rickinson, M., Teamey, K., Morris, M., Choi, M. ., Sanders, D., et al. (2006). The value of outdoor learning: Evidence from research in the UK and elsewhere. School Science Review, 87(320), 107-111.

Edje, O. (2004). "Indigenous knowledge systems: Its role in household foods security." Paper presented at a conference on Embracing Information Communication Technology in the Development of Indigenous Knowledge Systems in Swaziland. Esibayeni Lodge, Matsapha

FAO (2010). Global forest resources assessment. Food and Agriculture Organization of the United Nations, Rome.

Ferreira, J. (2009). Unsettling orthodoxies: Education for the environment/ for sustainability. Environmental Education Research, 15(5), 607-620.

Fien, J. (1993). Environmental Education: A pathway to sustainability. Victoria, Australia: Deakin University.

Gardner, F. (2009). Affirming values: Using critical reflection to explore meaning and professional practice. Reflective Practice, 10(2), 179-190.

Gough, A. (1997). Founders of environmental education: Narratives of the Australian environmental education movement. Environmental Education Research, 3(1), 43-57.

Israel, G., Coleman, D. L., Ilvento, T. (1993). Student involvement in community needs assessment. Journal of Community Development Society, 24(2), 249-271.

Kimaryo, L. (2011). Integration of environmental education in primary schools in Tanzania: Stockholm University Press, Stockholm.

Marcinkowski, T. J. (2010). Contemporary challenges and opportunities in environmental education: Where are we headed and what deserves our attention? Journal of Environmental Education, 41(1), 34-54.

Mosimege, M. (2005). National priorities in Indigenous Knowledge Systems: 114 Indigenous Knowledge in Disaster Management in Africa implications for research and curriculum development. Indilinga: African Journal of Indigenous Knowledge Systems (IAJIKS) 4(1), 31-37. 
O-sak, K. M. (1991). Factors Influencing the Use of the Environment in Science Teaching: A Study of Biology Teaching in Tanzania, Unpublished PhD thesis, University of Alberta, Canada.

Palmer, J., (1999). Environmental Education in the 21st Century: Theory, Practice, Progress, and Promise, Routledge.

Reynolds, M. (2011). Reflective practice: Origins and interpretations. Action Learning: Research and Practice, 8(1), 513.

Roth, R., Cantell, D., Bosquet, W. (1980). Impact on environmental education. In Hammerman, W. M. (ed.) Fifty years of resident outdoor education (1930-1980): Its impact on American education (p. 88). Martinsville, IN: American Camping Association.

Stenberg, K. (2010). Identity work as a tool for promoting the professional development of student teachers. Reflective Practice, 11(3), 331-346.

Stevenson, R. B. (2010). Environmental learning and agency in diverse educational and cultural contexts. In R. Stevenson \& J. Dillon (Eds.), Engaging environmental education: Learning, culture, and agency (pp. 219-238). Rotterdam: Sense Publishers.

URT (2007). National Strategy for Growth and Reduction of Poverty. Dar es Salaam: Government Printers.

Usang, E. (1992). Strategies for green literacy. In Convergence XVI(2), 44-5.

UNEP (2008). Methods Agenda 21 Chapter 36 - Promoting Education, Public Awareness and Training. 